\title{
A Five-Year Review of Perforated Peptic Ulcer Disease in Irrua, Nigeria
}

\author{
A. E. Dongo, ${ }^{1,2}$ O. Uhunmwagho, ${ }^{1,2}$ E. B. Kesieme, ${ }^{1,2}$ S. U. Eluehike, ${ }^{2,3}$ and E. F. Alufohai ${ }^{1,2}$ \\ ${ }^{1}$ Department of Surgery, Irrua Specialist Teaching Hospital, Irrua, Nigeria \\ ${ }^{2}$ Ambrose Alli University, Ekpoma, Nigeria \\ ${ }^{3}$ Department of Radiology, Irrua Specialist Teaching Hospital, Irrua, Nigeria
}

Correspondence should be addressed to A. E. Dongo; aedongo@yahoo.co.uk

Received 23 December 2016; Accepted 3 April 2017; Published 1 June 2017

Academic Editor: Roberto Cirocchi

Copyright (C) 2017 A. E. Dongo et al. This is an open access article distributed under the Creative Commons Attribution License, which permits unrestricted use, distribution, and reproduction in any medium, provided the original work is properly cited.

\begin{abstract}
Background. Peptic ulcer perforation is a common cause of emergency admission and surgery. This is the first study that documents the presentation and outcome of management in Irrua, Nigeria. Patients and Method. This is a prospective study of all patients operated on for perforated peptic ulcer between April 1, 2010, and March 31, 2015. A structured questionnaire containing patients' demographics, operation findings, and outcome was filled upon discharge or death. Results. There were 104 patients. 81 males and 23 females $(\mathrm{M}: \mathrm{F}=3.5: 1)$. The age range was between 17 years and 95 years. The mean age was 48.99 years \pm SD 16.1 years. The ratio of gastric to duodenal perforation was $1.88: 1$. Perforation was the first sign of peptic ulcer disease in 62 (59.6\%). Pneumoperitoneum was detectable with plain radiographs in 95 (91\%) patients. $72(69.2 \%)$ had Graham's Omentopexy. Death rate was 17.3\%. Conclusion. We note that gastric perforation is a far commoner disease in our environment. Perforation is often the first sign of peptic ulcer disease. We identify fasting amongst Christians as a risk factor for perforation.
\end{abstract}

\section{Introduction}

Peptic ulcer perforation is a life threatening complication of peptic ulcer disease occurring in about $2-14 \%$ of cases of peptic ulcer disease $[1,2]$. This perforation is either located in the lesser curvature of the stomach or on the anterior surface of the duodenum [3] resulting in a spillage of gastric contents into the peritoneal cavity. Perforation is one of the commonest causes of emergency hospitalization and surgery in peptic ulcer disease $[4,5]$.

The first clinical description of a perforated peptic ulcer was made in 1670 in princess Henrietta of England [6]. Since then several notable people have succumbed to this illness over the years [7]. The presentation may be dramatic with pain of sudden onset often severe and radiating to the back with rapidly supervening features of peritonitis in about twothirds of patients [8]. In this classical presentation the patient may recall the exact time of perforation, often in the early hours of the morning. Pain may sometimes be insidious in onset and sometimes mimic an acute appendicitis [9] when perforation is small and contents leak slowly into the right iliac fossa through the right paracolic gutter [3]. In elderly patients, or immunocompromised patients, the signs of perforation may be insidious or equivocal [10].

The diagnosis is made with a high index of suspicion with the main differential being an acute exacerbation in a patient with known peptic ulcer disease [11]. The presence of air under the diaphragm in an erect chest radiograph often clinches the diagnosis. This sign, present in up to $75 \%$ [12] of erect chest radiographs, is dependent on size of perforation and interval before presentation. The use of an erect lateral chest radiograph can improve detection of pneumoperitoneum to $98 \%$ [13]. Currently, the use of computerized tomographic scan is the gold standard for detection of perforation [14,15]. With ultrasonography, though easily accessible, and useful when radiation burden is critical [16], detection of pneumoperitoneum is difficult even for the skilled sonographer [17].

The aim of treatment is surgery after active resuscitation [18]. Few recent studies advocate nonoperative intervention except as a stop gap before definitive surgical intervention [11]. Recently, laparoscopic repair is being advocated when 
the expertise and equipment are available. Although outcome with open surgery is comparable [19], laparoscopic repair has the distinct advantage of reduced hospital stay as well as reduced postoperative pain and opiate requirement [20].

Nevertheless, in a resource-poor environment like ours, open surgery remains the only available option with either a simple closure or the use of an omental (graham's) patch [21] or champagne cork closure [22]. Because of our improved understanding of the pathogenesis of ulcers especially the role of Helicobacter pylori, the question of definitive antiulcer surgery at the same setting has few remaining indications [23-25]. When indicated [26], a careful evaluation of several factors like the presence of comorbidities, age, and the physiological state of the patient is required to improve mortality.

This study attempts to highlight the pattern of presentation and to document the outcome after surgical intervention in patients with perforated peptic ulcer disease in a rural community in mid-western Nigeria.

\section{Patients and Method}

This is a prospective study of all patients who had operative intervention for perforated peptic ulcers at the Irrua specialist teaching hospital over a 5-year period between April 1st, 2010, and March 31, 2015. Approval was sought and received from the ethics and research committee of the hospital before commencement of the study.

Irrua specialist teaching hospital is a 375-bedded hospital in Irrua, a rural community in mid-west Nigeria. It is about 100 kilometres from the state capital city of Benin. It serves principally the central and northern senatorial districts of Edo state and the neighbouring states of Ondo, Kogi, and Delta states. This population is about 3-4 million.

A questionnaire was filled by one of the authors or his residents within 3 days of surgery and upon discharge or death. Data collected include patient demographics, site and size of perforation, amount of pyoperitoneum interval before presentation, and type of surgery performed as well as treatment and outcome.

The diagnosis of perforated peptic ulcer was made on clinical grounds. This was confirmed at laparotomy. Patients were resuscitated with intravenous fluids and had baseline biochemical and hematological investigations done. Erect chest or lateral decubitus radiographs and abdominal ultrasound were carried out. No patient had computerized tomographic scan done as it was unavailable here during the period under study. All patients were catheterized and had nasogastric suction. Surgery was performed via a midline supraumbilical incision after adequate resuscitation. Simple closure or omentopexy was carried out with copious saline peritoneal lavage. The ulcer edge was excised for histology routinely. A drain was usually left in Morrison's pouch. All patients received triple regime antibiotics for 14 days for $H$. pylori eradication. Data were analyzed using SPSS 22 Statistical Package.

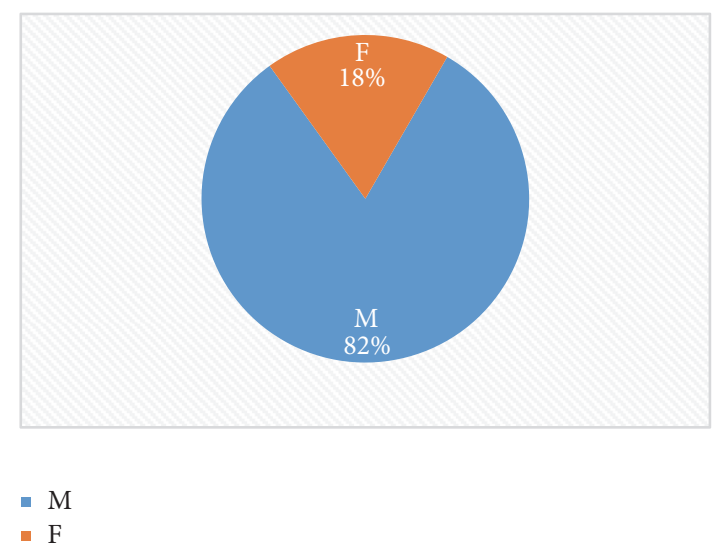

FIGURE 1: Pie chart showing gender distribution.

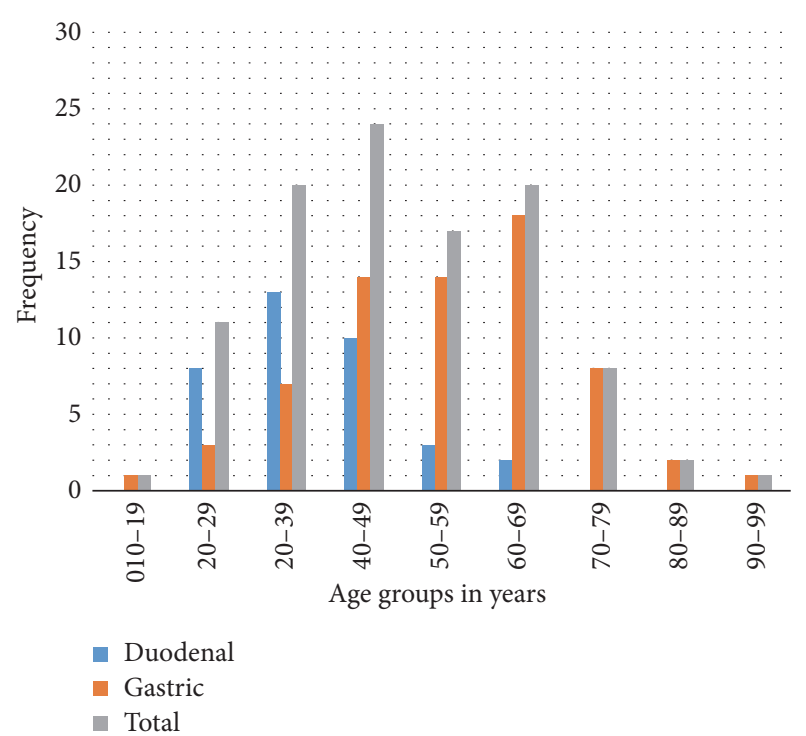

FIGURE 2: Bar chart showing age distribution and site of perforation.

\section{Results}

In the period under study, 104 patients had operative intervention for perforated peptic ulcer disease. There were eightyone (81) males and twenty-three (23) females, giving a male to female ratio of $3.5: 1$ (Figure 1). Sixty-eight (65\%) patients had perforated gastric ulcer while thirty-six (35\%) patients had perforated duodenal ulcer giving a gastric to duodenal ulcer ratio of $1.88: 1$. All patients had a single perforation.

The age range was between 17 years and 95 years (Figure 2). The mean age was 49.99 years with a standard deviation of 16.1 years. The mean age for the duodenal ulcer perforation was 37.75 years (SD 11.08 years). The mean age for gastric ulcer perforation was 55 years (SD 15.19 years).

A majority of patients, sixty-two (59.6\%), had no history of peptic ulcer disease and only forty-five patients (43.2\%) had admitted to taking any form of antiulcer medication within the last six months before perforation. Majority of the patients were from the lower socioeconomic groups. Farmers constituted the single largest group 41 (39.4\%); traders were 
TABLE 1: Occupation.

\begin{tabular}{lcc}
\hline Occupation & Number of patients & Frequency/percentage \\
\hline Farmers & 45 & 43.2 \\
Traders & 9 & 8.6 \\
Students & 7 & 6.7 \\
Pastors & 7 & 6.7 \\
Teachers & 5 & 4.8 \\
Others & 31 & 29.8 \\
\hline Total & 104 & 99.8 \\
\hline
\end{tabular}

TABLE 2: Clinical presentation and their frequency rate.

\begin{tabular}{lcc}
\hline Clinical presentation & Frequency & Percentage \\
\hline Pain & 104 & 100 \\
Vomiting & 70 & 67 \\
Fever & 32 & 31 \\
Constipation & 24 & 23.2 \\
Air under diaphragm & 95 & 91 \\
Abdominal distention & 64 & 61.5 \\
\hline
\end{tabular}

TABLE 3: Method of repair and frequency rate.

\begin{tabular}{lc}
\hline Repair method & Frequency (\%) \\
\hline Simple closure & $32(30.8)$ \\
Omental patch repair & $72(69.2)$ \\
\hline
\end{tabular}

12 (11.5\%); students were 8 (7.7\%); pastors and teachers were 6 each $(5.7 \%)$ (Table 1$)$.

The commonest mode of presentation was pain occurring in all the 104 patients (Table 2). The next commonest symptom was vomiting in $70(67 \%)$ patients. Fever occurred in only $32(31 \%)$ patients. Air under the diaphragm was found in 95 (91\%) patients from plain chest or erect lateral decubitus radiographs. Risk factors identified include NSAID use in 39 (37.5\%), including the youngest patient, ingestion of herbal concoctions in $18(17.3 \%)$, dry fasting in 6 (5.7\%), four pastors and two females, and smoking in 5 (4.8\%).

The sizes of perforation ranged in $<1 \mathrm{~cm}, 51(49 \%)$; between 1 and $2 \mathrm{~cm}, 39$ (37.5\%); and $>2 \mathrm{~cm}, 14$ (13.5\%). The quantity of pyoperitoneum at laparotomy ranged between (in litres) <1 L, 24 (23.1\%); 1 and $2 \mathrm{~L}, 57$ (54.8\%), and >2 L, $23(22.1 \%)$. The preferred method of repair was graham's omentopexy in $72(69.2 \%)$ patients (see Table 3$)$. The rest had simple closure of the edges. No patient had definitive antiulcer surgery. There were 9 reoperations, 4 for leakage of repair and 5 for intraabdominal collections with repair intact. None of the samples sent for histology revealed any malignancy.

Eighty-six patients $(82.7 \%)$ were discharged home and there were $18(17.3 \%)$ deaths in all. Two of the deaths had reoperations.

\section{Discussion}

In this study, a total of one hundred and six patients were operated on for gastroduodenal perforations. This gives an average of almost twenty-one cases annually. This figure is slightly higher in incidence than those described in Enugu Nigeria and some Eastern and Southern African series [2729]. It is to be expected that this may be an underrepresentation as several late cases may have succumbed to the disease before definitive surgery and are thus not captured.

We find that peptic ulcer perforation is predominantly a male affliction as males outnumbered females by a ratio of 3.5 to 1 . This finding is consistent with several others from Africa which confirm a male preponderance from a low $1.3: 1$ in Bugando, Tanzania [27], to a high ratio of $8.3: 1$ in Techiman, Ghana [22], and 14:1 in Ido Ekiti, Nigeria [30]. It is contrary to the common depiction in western series as a disease of the elderly female $[31,32]$.

In addition to the foregoing, there is the finding that peptic ulcer perforations affect a younger age group. The mean age for duodenal perforation is 37.75 , almost 20 years lower than for gastric perforations. More than $75 \%$ of all duodenal perforations occur before the age of 50 years. It is to be noted however that the youngest patient in this series had a gastric perforation while taking ibuprofen for 1 week for severe low back ache from farm work. This drug has been implicated in peptic ulceration even in the paediatric age group previously [33].

Unlike previous studies from Nigeria which reveal no cases of gastric ulcer perforation [27, 30, 34], we now report gastric ulcers outnumbering duodenal perforation by a ratio of about $2: 1$. Although a previous study from a municipal hospital in Ghana had shown a similar finding [22], several other African studies reveal a majority of duodenal perforation $[28,35,36]$. While we have no clear explanation for this changing epidemiological profile, we note that gastroduodenal ulcers share similar pathogenesis especially of $H$. pylori infestation [37] which is commoner in younger patients in the lower socioeconomic rung [38]. Studies from Southern and Northern Nigeria confirm a high prevalence of $81.4 \%$ when using urease culture tests for antral biopsies and as high as over $90 \%$ with serological tests amongst dyspeptic patients $[39,40]$. Although testing for $H$. pylori was unavailable in our centre during this study, all patients with perforated ulcers received eradication therapy for $H$. pylori. It is also known that abuse of nonsteroidal anti-inflammatory agents which we found in as high as $37.5 \%$ is a major etiologic agent especially in gastric ulceration. Other risk factors identified include use of herbal remedies previously alluded to by other workers and "dry" fasting. Dry fasting is described as fasting without drinking water or eating.

This study has found that perforation may be the first symptom of peptic ulcer disease since as much as three out of every five patients had no previous dyspeptic symptoms. It had been highlighted previously that diagnosis of peptic ulcer disease is only made after perforation in many developing countries [41]; only $43 \%$ of patients had admitted to taking any form of antiulcer medications in the 6 months preceding perforation. This figure is slightly higher than the $31 \%$ reported in Enugu, Nigeria, of perforations in patients known to have chronic peptic ulcer disease [27]. This finding has the distinct advantage of increasing the index of suspicion of perforation compared to acute exacerbation of peptic 
ulcer which may delay definitive surgical intervention. With perforation, however, we note that pain was universal in our series occurring in $100 \%$ of cases followed by vomiting in $71 \%$. This finding is similar to Chalya et al. [28] who observed these two leading presenting features. Fever is a far less prevalent symptom in our patients occurring in only $31 \%$ of our patients. This finding may be due to the use of analgesics with antipyretic properties.

In the period under study, our centre had no computerized tomographic scan; inspite of this, this study shows a high detection rate of pneumoperitoneum of $91 \%$. This is higher than what other studies suggest $[12,28]$ but similar to that found in Ghana $[22,36]$. Late presentation may play a role as radiographic detection of pneumoperitoneum improves when interval between perforation and radiologic examination is long [42]. While multidetector CT has the distinct advantage of providing direct evidence of site gastrointestinal discontinuity [43] assisting in determining the best surgical option preoperatively in perforated peptic ulcers [44] we contend that, in our setting, plain radiographs are sufficient in the emergency patient with sudden onset epigastric pain as some workers have suggested [45].

In a rural community such as ours, understandably, majority of our patients would be in the lower socioeconomic groups. But this study identifies another risk group, clergymen or pastors. Four pastors over a five-year period were operated upon for perforated peptic ulcers. They all had gastric perforation and were all males. They were in the midst of dry fasting for between 3 and 7 days before they perforated. Two others, females one with duodenal and another with gastric perforation, were also admitted with symptoms while on a fast. Several studies in the past have documented the increased frequency of peptic ulcer and its complications during Ramadan fast [46-48]. Unlike the partial hunger that exists during Ramadan, a dry fast is likely to produce a higher frequency of complications within a shorter time frame from onset of fasting.

This study has shown that a repair with an omental patch or simple repair produces acceptable results even for ulcers that are relatively large as $13.5 \%$ of our patients had ulcers larger than $2 \mathrm{~cm}$ in diameter. Of the 9 patients who had reoperations after the procedure, 5 were found to have an intact repair at subsequent surgery. Two patients had fibrosis around the ulcer margin at the initial surgery and despite excision of the ulcer edges and a pedicled omental patch there was a leakage.

The overall mortality in our series of $17.3 \%$ is within the range $4-30 \%$ widely quoted in many series [49-51]. Two of our patients died after reoperations. Two died from pulmonary embolism. The rest from septicaemia, adult respiratory distress syndrome, and multiple organ failure.

In conclusion we note that perforated peptic ulcer is a common surgical problem in our environment. A majority of such perforations are gastric in nature and such perforations are the first sign of peptic ulcer disease in a majority of the patients. A plain chest radiograph is sufficient to make the diagnosis in the classic case of sudden onset epigastric pain. We identify fasting as an emerging risk factor for perforation amongst Christians.

\section{Conflicts of Interest}

The authors declare that they have no conflicts of interest.

\section{Authors' Contributions}

A. E. Dongo conceived the study and its design and participated in data collection and coordination as well as draft of manuscript. O. Uhunmwagho, E. B. Kesieme, S. U. Eluehike, and E. F. Alufohai participated in design of study and review of manuscript. All authors have read and approved the final version of the manuscript.

\section{Acknowledgments}

The authors wish to thank Dr. T. Kweki for technical assistance in designing the figures and Mrs. Vivian Ijeh for her secretarial assistance.

\section{References}

[1] M. J. O. E. Bertleff and J. F. Lange, "Perforated peptic ulcer disease: a review of history and treatment," Digestive Surgery, vol. 27, no. 3, pp. 161-169, 2010.

[2] J.-Y. Lau, J. Sung, C. Hill, C. Henderson, C. W. Howden, and D. C. Metz, "Systematic review of the epidemiology of complicated peptic ulcer disease: incidence, recurrence, risk factors and mortality," Digestion, vol. 84, no. 2, pp. 102-113, 2011.

[3] N. Williams, C. Bullstrode, and P. O'Connell, Stomach and Duodenum in Bailey and Love's Short Practice of Surgery, CRC, London UK, 26th edition, 2013.

[4] Y. R. Wang, J. E. Richter, and D. T. Dempsey, "Trends and outcomes of hospitalizations for peptic ulcer disease in the united states, 1993 to 2006," Annals of Surgery, vol. 251, no. 1, pp. 51-58, 2010.

[5] H. Güzel, Ş. Kahramanca, D. Şeker et al., "Peptic ulcer complications requiring surgery: what has changed in the last 50 years in Turkey," Turkish Journal of Gastroenterology, vol. 25, no. 2, pp. 152-155, 2014.

[6] T. Milosavljevic, M. Kostić-Milosavljević, I. Jovanović, and M. Krstić, "Complications of peptic ulcer disease," Digestive Diseases, vol. 29, no. 5, pp. 491-493, 2011.

[7] Perforated ulcers. Notable cases, 2017, http://en.m.wikipedia .org/wiki/perforated_ulcer.

[8] B. I. Hirschowitz, J. Simmons, and J. Mohnen, "Clinical outcome using lansoprazole in acid hypersecretors with and without Zollinger-Ellison syndrome: a 13-year prospective study," Clinical Gastroenterology and Hepatology, vol. 3, no. 1, pp. 39-48, 2005.

[9] M. King, P. C. Bewes, J. Cairns, and J. Thornton, Perforated gastric or duodenal ulcer in primary surgery, vol. 1, ena GTZ $(\mathrm{GmbH})$, Jena, 1999.

[10] S. M. Fakhry, D. D. Watts, and F. A. Luchette, "Current diagnostic approaches lack sensitivity in the diagnosis of perforated blunt small bowel injury: analysis from 275,557 trauma admissions from the EAST multi-institutional HVI trial," The Journal of Trauma: Injury, Infection, and Critical Care, vol. 54, no. 2, pp. 295-306, 2003.

[11] S. Di Saverio, M. Bassi, N. Smerieri et al., "Diagnosis and treatment of perforated or bleeding peptic ulcers: 2013 WSES 
position paper,' World Journal of Emergency Surgery, vol. 9, article 45, 2014.

[12] M. Mehboob, J. A. Khan, Rehman Shafiq-ur, S. M. Saleem, and A. Abdul Qayyum, Peptic Duodenal Perforation-an Audit, vol. $6,103,101,2000$.

[13] J. H. Woodring and M. J. Heiser, "Detection of pneumoperitoneum on chest radiographs: comparison of upright lateral and posteroanterior projections," American Journal of Roentgenology, vol. 165, no. 1, pp. 45-47, 1995.

[14] S. R. Baker, "Imaging of pneumoperitoneum," Abdominal Imaging, vol. 21, no. 5, pp. 413-414, 1996.

[15] V. Maniatis, H. Chryssikopoulos, A. Roussakis et al., "Perforation of the alimentary tract: Evaluation with computed tomography," Abdominal Imaging, vol. 25, no. 4, pp. 373-379, 2000.

[16] F. F. Coppolino, G. Gatta, G. Di Grezia et al., "Gastrointestinal perforation: Ultrasonographic diagnosis," Crit Ultrasound J, vol. 5, supplement 1, article S4, 2013.

[17] K. Seitz and Reising K. D., Reising KD. Ultrasound detection of free air in the abdominal cavity. Ultraschall Med, vol. 5, 4-6, 5(1, 1982.

[18] M. H. Møller, S. Adamsen, R. W. Thomsen, and A. M. Møller, "Multicentre trial of a perioperative protocol to reduce mortality in patients with peptic ulcer perforation," British Journal of Surgery, vol. 98, no. 6, pp. 802-810, 2011.

[19] R. Lunevicius and M. Morkevicius, "Comparison of laparoscopic versus open repair for perforated duodenal ulcers," Surgical Endoscopy and Other Interventional Techniques, vol. 19, no. 12, pp. 1565-1571, 2005.

[20] A. E. Sanabria, C. H. Morales, and M. I. Villegas, "Laparoscopic repair for perforated peptic ulcer disease," Cochrane Database of Systematic Reviews, no. 4, Article ID CD004778, 2005.

[21] R. Graham, “The treatment of perforated duodenal ulcers. Surg Gynec Obstect," Surg Gynec Obstec, vol. 64, pp. 235-238, 1937.

[22] H. H. Wegdam and A. A. Hillah, Modified open omental plugging of peptic ulcer perforation in a municipal hospital in Ghana: $P M J G$, vol. 2, Hillah AA. Modified open omental plugging of peptic ulcer perforation in a municipal hospital in Ghana, PMJG, 2013.

[23] C. W. Lee and G. A. Sarosi, "Emergency ulcer surgery," Surgical Clinics of North America, vol. 91, no. 5, pp. 1010-1016, 2011.

[24] E. K. Ng, Y. H. Lam, J. J. Sung et al., "Eradication of Helicobacter pylori prevents recurrence of ulcer after simple closure of duodenal ulcer perforation: randomised control trial," Ann Surg, vol. 221, no. 2, pp. 153-158, 2000.

[25] C. Gutiérrez De La Peña, R. Maŕquez, F. Fakih, E. DomínguezAdame, and J. Medina, "Simple closure or vagotomy and pyloroplasty for the treatment of a perforated duodenal ulcer: Comparison of results," Digestive Surgery, vol. 17, no. 3, pp. 225228, 2000.

[26] Dempsey D. T., "Stomach," F. C. Brunicardi, D. K. Anderson, T. R. Billiar, D. L. Duncan, J. G. Hunter, and R. E. Pollock, Eds., pp. 968-969, The Mcgraw-Hill companies Inc.

[27] A. I. Ugochukwu, O. C. Amu, M. A. Nzegwu, and U. C. Dilibe, "Acute perforated peptic ulcer: on clinical experience in an urban tertiary hospital in south east Nigeria," International Journal of Surgery, vol. 11, no. 3, pp. 223-227, 2013.

[28] P. L. Chalya, J. B. Mabula, M. Koy et al., "Clinical profile and outcome of surgical treatment of perforated peptic ulcers in northwestern Tanzania: a tertiary hospital experience," World Journal of Emergency Surgery, vol. 6, article 31, 2011.
[29] M. Shein and R. Saadia, "Perforated peptic ulcer at the J.G Strijdom hospital: a retrospective study of 99 patients," $S$ Afr Med J, vol. 70, no. 5, pp. 21-23, 1986.

[30] F. O. Oribhabor, B. O. Adebayo, and T. Aladesanmi, "Akinola DO: Perforated duodenal Ulcer; Management in a resource poor, semi-urban Nigerian Hospital," in rian Hospital. Niger J Surg, vol. 19, p. 13, semi-urban ian Hospital. J Surg, Niger, 2013.

[31] J. Y. Kang, A. Elders, A. Majeed, J. D. Maxwell, and K. D. Bardhan, "Recent trends in hospital admissions and mortality rates for peptic ulcer in Scotland 1982-2002," Alimentary Pharmacology and Therapeutics, vol. 24, no. 1, pp. 65-79, 2006.

[32] K. Thorsen, T. B. Glomsaker, A. von Meer, K. Søreide, and J. A. Søreide, "Trends in diagnosis and surgical management of patients with perforated peptic ulcer," Journal of Gastrointestinal Surgery, vol. 15, no. 8, pp. 1329-1335, 2011.

[33] S. H. Berezin, H. E. Bostwick, M. S. Halata, J. Feerick, L. J. Newman, and M. S. Medow, "Gastrointestinal bleeding in children following ingestion of low-dose ibuprofen," Journal of Pediatric Gastroenterology and Nutrition, vol. 44, no. 4, pp. 506508, 2007.

[34] A. Nuhu and Y. Kassama, "Experience with acute perforated duodenal ulcer in a West African population," Nigerian Journal of Medicine, vol. 17, no. 4, pp. 403-406, 2008.

[35] S. K. Gona, M. K. Alassan, K. G. Marcellin et al., "Postoperative Morbidity and Mortality of Perforated Peptic Ulcer: Retrospective Cohort Study of Risk Factors among Black Africans in Côte d'Ivoire," Gastroenterology Research and Practice, vol. 2016, Article ID 2640730, 2016.

[36] J. C. B. Dakubo, S. B. Naaaeder, and J. N. Clegg-Lamptey, "Gastroduodenal peptic ulceration," East Afr med J, vol. 86, no. 3, pp. 100-109, 2009.

[37] P. Malfertheiner, F. K. Chan, and K. E. McColl, "Peptic ulcer disease," The Lancet, vol. 374, no. 9699, pp. 1449-1461, 2009.

[38] J. P. Gisbert, J. Legido, I. García-Sanz, and J. M. Pajares, "Helicobacter pylori and perforated peptic ulcer. Prevalence of the infection and role of non-steroidal anti-inflammatory drugs," Digestive and Liver Disease, vol. 36, no. 2, pp. 116-120, 2004.

[39] B. A. Adeniyi, J. A. Otegbayo, T. O. Lawal, A. O. Oluwasola, G. N. Odaibo, and C. Okolo, "Prevalence of Helicobacter pylori infection among dyspepsia patients in Ibadan," AJMR, vol. 14, pp. 3399-402, 2012.

[40] B. M. Tijani, M. M. Borodo, A. A. Samalia, and B. Umar, "Association of helicobacter pylori infection with peptic ulcer in Kano Nigeria," Nig J of Gastro hepatol, vol. 2, article 1, 2010.

[41] O. G. Ajao, "Perforated duodenal ulcer in a tropical African population," J Natl Med Assoc, vol. 71, p. 272, 1979.

[42] S. Oguro, T. Funabiki, K. Hosoda et al., "64-slice multidetector computed tomography evaluation of gastrointestinal tract perforation site: Detectability of direct findings in upper and lower GI tract," European Radiology, vol. 20, no. 6, pp. 1396-1403, 2010.

[43] S. Y. Wang, C. T. Cheng, C. T. Liad, Fu. CY, Y. C. Wong, H. W. Chen et al., "Surgical planning in Perforated peptic ulcer," Am J Surg, vol. 21, no. 4, pp. 755-61, Surgical planning in Perforated peptic ulcer. Am, 755-61,

[44] R. Grassi, S. Romano, A. Pinto, and L. Romano, "Gastroduodenal perforations: conventional plain film, US and CT findings in 166 consecutive patients," European Journal of Radiology, vol. 50, no. 1, pp. 30-36, 2004.

[45] S. B. Khan, N. Riaz, N. Afza et al., "Perforated Peptic Ulcers: A review of 36 cases," Professional Med J, vol. 18, pp. 124-27, 2011. 
[46] BM. Gali, AG. Ibrahim, CM. Chama et al., "Perforated peptic ulcer (, pp. U-in pregnancy during ramadan fasting," Niger $J$ med, ., Oct-dec, vol. 20, no. 4, p. 497, 2011.

[47] A. K. Gökakin, A. Kurt, M. Atabey et al., "The impact of Ramadan on peptic ulcer perforation," Ulusal Travma ve Acil Cerrahi Dergisi, vol. 18, no. 4, pp. 339-343, 2012.

[48] G. M. Malik, M. Mubarik, G. Jeelani et al., "Endoscopic Evaluation of Peptic Ulcer Disease During Ramadan Fasting: A Preliminary Study," Diagnostic and Therapeutic Endoscopy, vol. 2, no. 4, pp. 219-221, 1996.

[49] H. Paimela, N. K. J. Oksala, and E. Kivilaakso, "Surgery for peptic ulcer today: a study on the incidence, methods and mortality in surgery for peptic ulcer in Finland between 1987 and 1999," Digestive Surgery, vol. 21, no. 3, pp. 185-191, 2004.

[50] C. Svanes, H. Salvesen, L. Stangeland, K. Svanes, and O. Søreide, "Perforated peptic ulcer over 56 years. Time trends in patients and disease characteristics," Gut, vol. 34, no. 12, pp. 1666-1671, 1993.

[51] T. T. Zittel, E. C. Jehle, and H. D. Becker, "Surgical management of peptic ulcer disease today-indication, technique and outcome," Langenbeck's Archives of Surgery, vol. 385, no. 2, pp. 8496, 2000. 


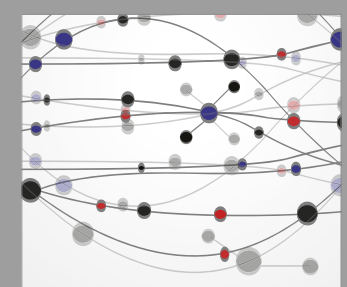

The Scientific World Journal
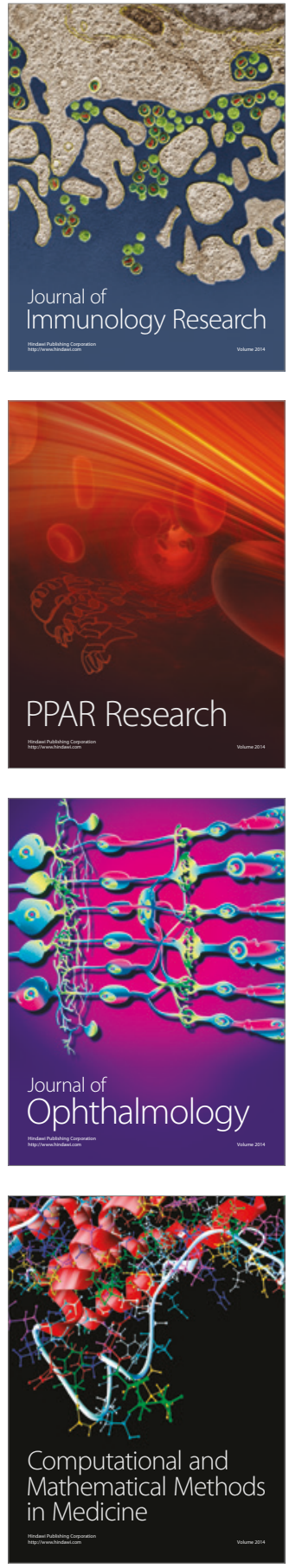

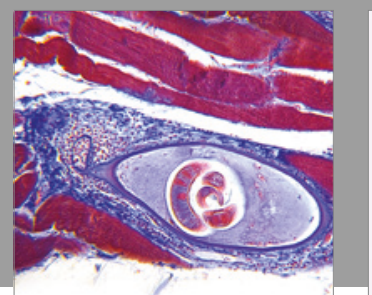

Gastroenterology Research and Practice
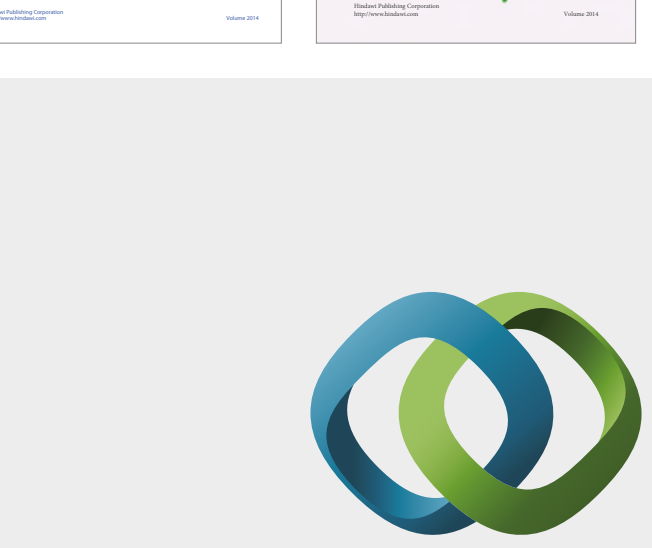

\section{Hindawi}

Submit your manuscripts at

https://www.hindawi.com
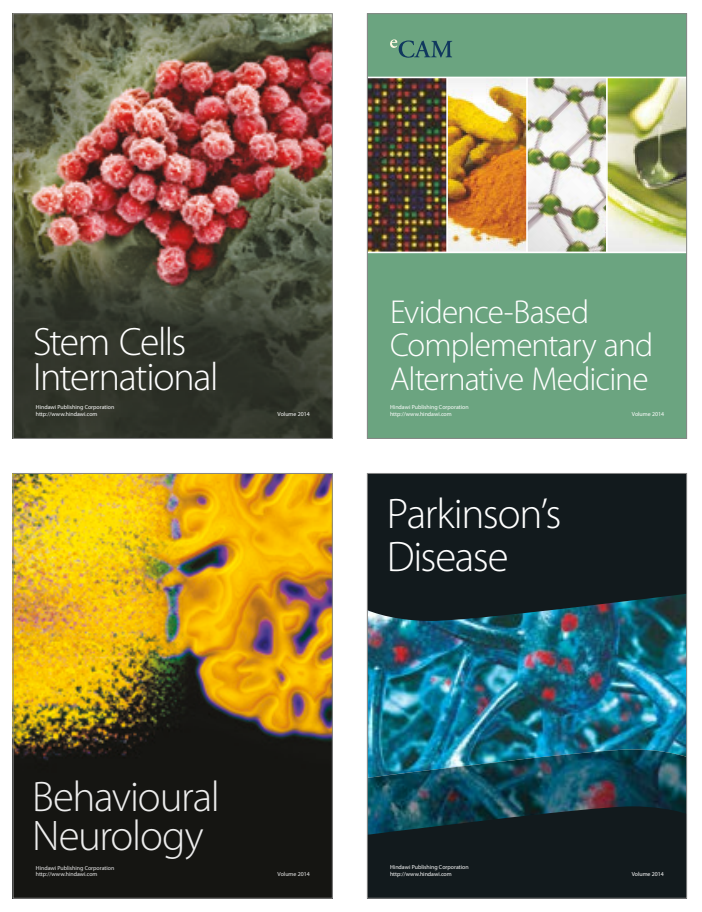
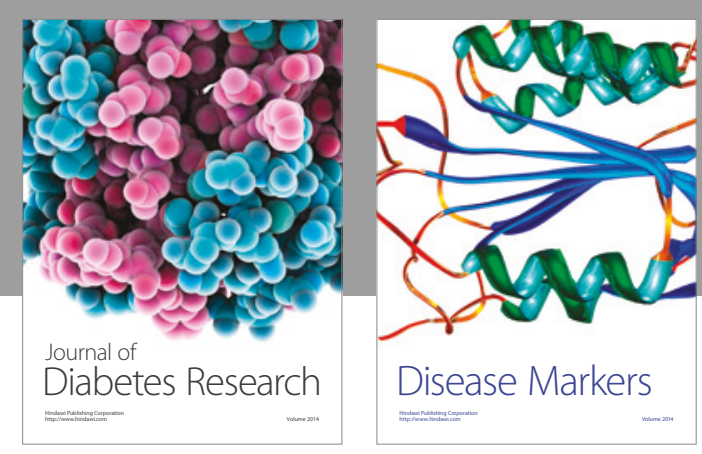

Disease Markers
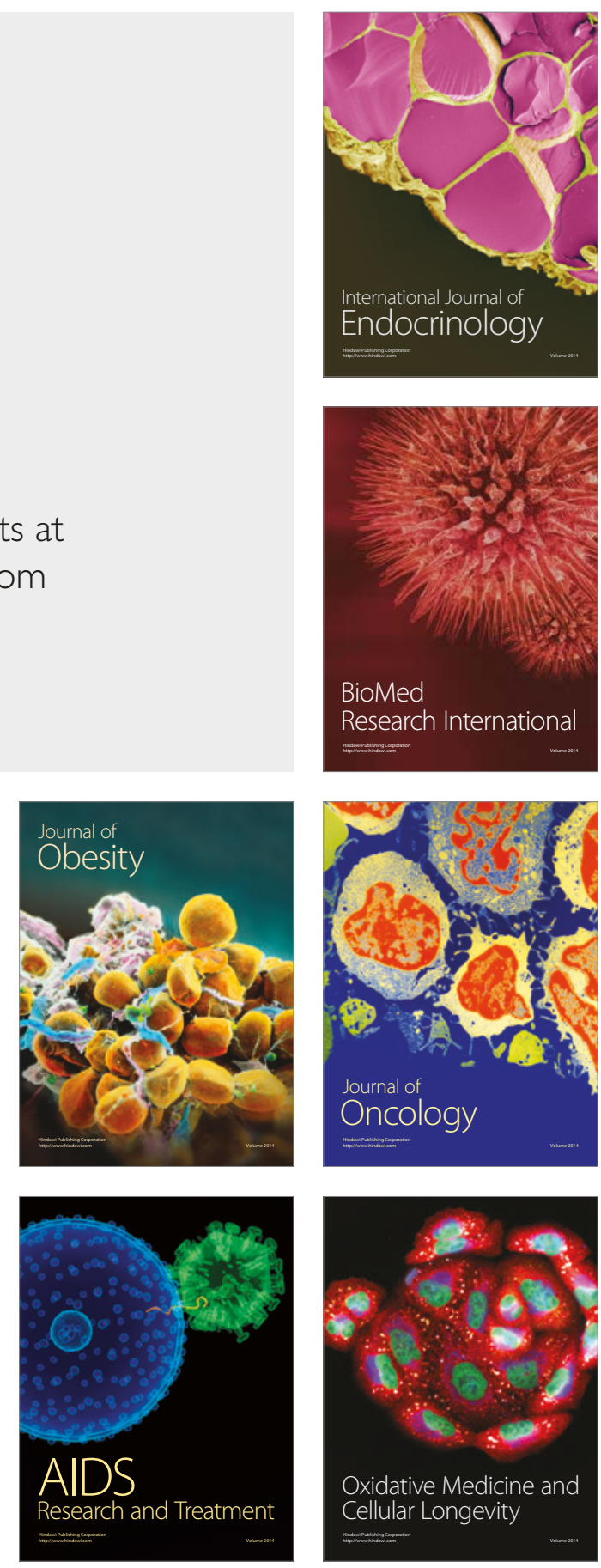